\title{
ENTREVISTA COM 0 FÍSICO MARCELO GLEISER
}

\author{
Stela Guedes Caputo (UERJ)* \\ http://orcid.org/0000-0003-0133-3301
}

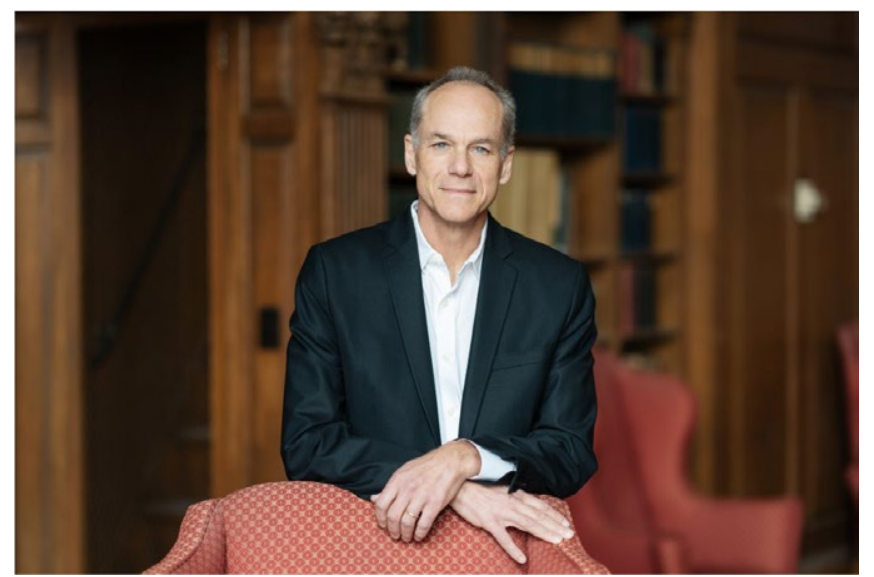

\section{RESUMO}

0 governo do presidente brasileiro Jair Bolsonaro aprofunda cada vez mais o desprezo pelo conhecimento, que ele já manifestava desde a campanha eleitoral. Em plena pandemia da Covid-19, enquanto o mundo aposta nas pesquisas científicas, na esperança da descoberta de vacinas (o que já aconteceu), Bolsonaro intensifica sua cruzada contra as universidades e a ciência, rejeitando dados analisados com métodos e protocolos, ignorando pesquisas e orientações médicas mundiais, ou seja, sendo negacionista. Interesses financeiros de grandes grupos econômicos, obscurantismo religioso, imensa desigualdade social, um profundo descaso pela vida e o negacionismo, já mencionado, são algumas características do bolsonarismo que faz o Brasil agonizar nesse momento. Para conversar sobre esse ataque à ciência e aos cientistas, entrevistamos o físico e astrônomo brasileiro Marcelo Gleiser, professor titular de filosofia natural e de física e astronomia na Dartmouth College, em Hanover, Estados Unidos, vencedor do Prêmio Templeton de 2019. Na entrevista, Gleiser fala sobre a importância do diálogo entre fé e ciência; sobre o papel das associações de pesquisas nesse momento; sustenta que o modelo cultural científico precisa mudar e se tornar menos eurocêntrico e mais pluralista; diz que o Brasil vive uma tragédia provocada pelo obscurantismo religioso e afirma que as novas gerações vão rir muito da nossa, em que muita gente ainda acredita que a Terra é plana.

Palavras-chave: Covid-19. Fé e ciência. Obscurantismo religioso. Pandemia. Bolsonarismo.

* Doutora em Educação pela Pontifícia Universidade católica do Rio de Janeiro (PUC-RIO). Professora do Programa de PósGraduação em Educação da Universidade do Estado do Rio de Janeiro (UERJ). E-mail: stelauerj@gmail.com 


\section{ABSTRACT}

\section{INTERVIEW WITH THE PHYSICS MARCELO GLEISER}

Brazilian president Jair Bolsonaro's government deepens even more the disdain for knowledge, which has been manifested since the election campaign. In the middle of the Covid-19 pandemic, while the world is relying on scientific research in the hope to find a cure, Bolsonaro, as a typical negationist, intensifies his crusade against universities and science by rejecting data analysed through methods and protocols and ignoring worldwide medical research and guidance. Financial interests of large economic groups, religious obscurantism, the country's vast social inequality, a profound disregard for life and negationism are some of the characteristics of "bolsonarism", which is currently making Brazil agonize. In order to discuss the attack on science and scientists, we interviewed Brazilian physicist and astronomer, Marcelo Gleiser, full professor of Natural Philosophy, Physics and Astronomy at Dartmouth College in Hanover, United States, and winner of the 2019 Templeton Award. In the interview, Gleiser speaks about the importance of the dialogue between faith and science; about the role of research associations at the present time; states that the scientific cultural model must change and become less Eurocentric and more pluralistic; declares that Brazil is experiencing a tragedy caused by religious obscurantism and affirms that the new generations will laugh a lot at ours, in which many people still believe that the Earth is flat.

Keywords: Covid-19. Faith and science. Religious obscurantism. Pandemic. Bolsonarism.

\section{RESUMEN}

\section{ENTREVISTA REALIZADA AL FÍSICO MARCELO GLEISER}

El gobierno del presidente brasileño Jair Bolsonaro profundizó cada vez más en el desprecio por el conocimiento que ya manifestaba desde la campaña electoral. En plena pandemia del Covid-19, mientras el mundo apuesta por las investigaciones científicas, por la esperanza del descubrimiento de una cura, Bolsonaro intensifica su enfrentamiento contra las universidades y la ciencia, rechazando los datos analizados con métodos y protocolos, ignorando las investigaciones y las orientaciones médicas mundiales, o sea, siendo negacionista. Los intereses financieros de grandes grupos económicos, el oscurantismo religioso, la desigualdad social inmensa, un gran descarte por la preservación de la vida y el negacionismo, ya mencionado, son algunas de las características del bolsonarismo que hace a Brasil agonizar en este momento. Para conversar sobre este ataque a la ciencia y a los científicos, entrevistamos al físico y astrónomo brasileño, Marcelo Gleiser, profesor titular de filosofía natural y de física y astronomía en la Dartmouth College, en Hanover, Estados Unidos, ganador del Premio Templeton, de 2019. En la entrevista, Gleiser habla sobre la importancia del diálogo entre la fe y la ciencia; sobre el papel de las asociaciones de investigación en este momento; sostiene que el modelo cultural científico necesita cambiar y tornarse menos eurocéntrico y más plural; comenta que Brasil vive una tragedia provocada por el oscurantismo religioso y afirma 
que las nuevas generaciones se reirán mucho de la nuestra, en la que mucha gente aún cree que la Tierra es plana.

Palabras clave: Covid-19. Fe y ciencia. Oscurantismo religioso. Pandemia. Bolsonarismo.

\section{Apresentação}

Fé e ciência sempre disputaram explicações fundamentais para o mundo ao longo da História. Conflito com desfechos trágicos, como para o cientista italiano Giordano Bruno, julgado e queimado vivo pela Inquisição em 1600. Seu "crime" foi combater dogmas religiosos e manter sua defesa da teoria do astrônomo e matemático Nicolau Copérnico: era a Terra que girava em torno do sol e não o contrário, como queria a Igreja. Um desfecho menos trágico teve o astrônomo, também italiano, Galileu Galilei. Julgado em 1633, foi obrigado a negar suas ideias, entre elas a mesma teoria copernicana, e condenado a passar o resto da vida em prisão domiciliar. Morreu em casa, em 1642, ao menos não foi queimado vivo, mas muitos outros pensadores foram julgados e executados pela Inquisição. Para o físico e astrônomo brasileiro Marcelo Gleiser (1997), dos inúmeros conflitos entre ciência e religião, nenhum teve mais atenção do que a batalha entre Galileu e a Igreja Católica. A importância desse episódio é tamanha que, em 1982, diz Gleiser, o Papa João Paulo II defendeu em discurso a necessidade de um estudo mais profundo sobre esse caso para remover possíveis obstruções a uma relação frutífera entre ciência e fé. No mesmo discurso, João Paulo II afirma a existência de dois reinos do conhecimento. Um seria a fé, cuja fonte é a revelação divina, outro a razão, sustentada pelas ciências experimentais e a filosofia. Para João Paulo II, a distinção entre os dois modos de conhecimento não precisa ser entendida como oposição. Finalmente, em 1992, 360 anos depois de sentenciado, Galileu teve sua condenação revogada pela Igreja.

Marcelo Gleiser é professor titular de filosofia natural e de física e astronomia na Dartmouth College, em Hanover, Estados Unidos. É também um dos cientistas que mais defende a posição de que ciência e fé são caminhos complementares para a humanidade. "Negar uma ou outra é ignorar que o homem é tanto um ser espiritual quanto racional", escreveu em artigo publicado na Folha de São Paulo (GLEISER, 2006). Ele também está convicto da necessidade de uma postura menos binarista entre esses dois aspectos do humano, que possibilite uma convivência mais harmônica, desde que cada lado entenda e ocupe seu papel social.

Não existe nenhum conflito em uma justificativa religiosa ou espiritual para o trabalho científico, contanto que o produto desse trabalho satisfaça às regras impostas pela comunidade científica. $\mathrm{A}$ inspiração para se fazer ciência é completamente subjetiva e varia de cientista para cientista. Mas o produto de suas pesquisas tem um valor universal, fato que separa claramente a ciência da religião. (GLEISER, 1999, p. 47).

Por todo seu trabalho, o físico brasileiro foi o vencedor do Prêmio Templeton de 2019. Estabelecida em 1972, a distinção é uma condecoração anual atribuída pela Fundação John Templeton e entregue a uma pessoa viva que, na opinião dos juízes, “[...] teve uma contribuição excepcional para a afirmação da dimensão espiritual da vida, seja através de uma introspecção, descoberta ou trabalhos práticos" (JOHN TEMPLETON FOUNDATION, 2019). Grandes cientistas estão entre os premiados: Paul Davies, em 1995; Freeman Dyson, em 2000; John David Barrow, em 2006; Martin Rees, em 2011. O vencedor de 2020 foi o geneticista Francis Collins, comprometido na luta contra a Covid-19, líder do Projeto Genoma Humano nos Estados Unidos. Importantes líderes religiosos também já venceram: Madre Teresa de Calcutá, em 1973; Dalai Lama, em 2012; Reverendo Desmon Tutu, em 2013. 
Natural do Rio de Janeiro, Marcelo Gleiser se formou em física pela Pontifícia Universidade Católica do Rio de Janeiro (PUC-RJ), fez mestrado na Universidade Federal do Rio de Janeiro (UFRJ) e doutorado em cosmologia no King's College London, na Inglaterra. Suas principais questões de pesquisa envolvem a cosmologia, e a esse respeito já publicou mais de 100 artigos científicos e diversos livros, entre eles: $A$ dança do Universo (GLEISER, 1997); Retalhos cósmicos (GLEISER, 1999); O fim da Terra e do céu (GLEISER, 2001); Criação imperfeita (GLEISER, 2009); A ilha do conhecimento (GLEISER, 2014); A simples beleza do inesperado (GLEISER, 2016).

Preocupado com o obscurantismo que a sociedade brasileira atravessa, em especial nesse momento de pandemia, Marcelo Gleiser concedeu a entrevista que publicamos a seguir. Por e-mail, o cientista e escritor, além de retomar o tema do papel da ciência e da fé, afirmou que o obscurantismo brasileiro, protagonizado pelo presidente da república Jair Bolsonaro, trará efeitos devastadores para o Brasil. Defendeu a importância do papel dos cientistas e da urgência de uma mobilização e unidade maior entre as várias associações de pesquisa e disse que o modelo cultural científico precisa mudar, se tornar menos eurocêntrico e mais pluralista. Gleiser também falou de um novo Iluminismo em que a justiça social seja o foco, anunciando, inclusive, que esse será o tema de seu próximo livro, escrito com o filósofo Evan Thompson e o astrofísico Adam Frank.

Com certeza, você deve acompanhar a luta que travamos hoje, no Brasil, contra o obscurantismo religioso. Não só um obscurantismo que, já há tempos, violenta o Estado laico e outras religiões minoritárias, mas um obscurantismo que, em plena pandemia de coronavírus, produz uma cruzada contra a Ciência. Como você define o obscurantismo e de onde ele vem? Como se espalha?

GLEISER - 0 obscurantismo faz parte de um movimento para abalar estruturas de poder, inspirado, no Brasil, pela atual Presidência da República. 0 mesmo ocorre nos Estados Unidos com Trump e os resultados, como podemos ver com os dois maiores índices de casos de Covid-19 do mundo, são devastadores. Com a explosão da internet, onde todo mundo tem uma voz, ficou infinitamente mais fácil para charlatães e oportunistas usarem esse momento de falta de liderança para se lançarem como os novos profetas do não-saber. "Vamos destruir o meio-ambiente, vamos destruir o financiamento da pesquisa científica, vamos destruir a credibilidade dos cientistas para então tomar conta do país da forma mais predatória possível". O que eles não entendem é que estão assinando a própria sentença de morte - se não corporal, certamente intelectual - e, com eles, o país todo afunda.

No dia 16 de maio, apoiadores de Bolsonaro cantaram uma paródia da música "Florentina de Jesus", do palhaço Tiririca, em frente ao Palácio da Alvorada. A versão dos fanáticos viralizou na internet e ficou assim: "Cloroquina, Cloroquina. Cloroquina lá do SUS. Eu sei que tu me curas, em nome de Jesus." Como você acha que chegamos a esse ponto? É possível mensurar as consequências nacionais e internacionais para o Brasil diante disso? $\mathrm{E}$ como podemos reverter essa tragédia?

GLEISER - Tragédia mesmo. Porque esse fanatismo religioso, e é mesmo uma forma de fanatismo religioso, historicamente tem um enorme poder destruidor. A negação da ciência é uma ponte direta ao obscurantismo, é optar por voltar no tempo. De onde vem isso? Do desespero social, da percepção da perda de poder pela população, que se sente deixada para trás, sem líderes capazes de inspirar um crescimento econômico e cultural. No desespero da falta de recursos, sem visão de como vão prosperar nas suas vidas, aderem a esse tipo de anarquia cega. "Se eu afundo, afundam todos comigo". Para reverter isso, os diversos cientistas e intelectuais têm que 
se mobilizar e criar um contra-movimento, uma chamada a um novo Iluminismo em que a justiça social seja o foco.

Sim, o Iluminismo lutou contra o dogmatismo religioso, o obscurantismo. Mas você mesmo já disse em artigos que, ao ter como projeto uma civilização com "valores universais compartilhados por todos", o Iluminismo colocou o homem branco no ápice da sociedade. Que autocríticas a própria ciência e o projeto iluminista precisam fazer para que esse novo Iluminismo seja, de fato, mais humano e plural, e consiga ter a justiça social como foco?

GLEISER - Excelente pergunta. O modelo cultural científico precisa mudar, se tornar menos eurocêntrico e mais pluralista; e entender algo essencial, que, aliás, será o tema de meu próximo livro, escrito com o filósofo Evan Thompson e o astrofísico Adam Frank: que nunca podemos eliminar a experiência humana como ponto de partida de tudo o que fazemos, inclusive a construção de uma narrativa científica. Não existe uma visão "divina" do observador. 0 "novo iluminismo" é o que chamo de Humanocentrismo em meus livros, uma doutrina que também pretendo expandir em publicações futuras. Só quando entendermos a centralidade da humanidade e da vida (biocentrismo talvez seja melhor), e a raridade da Terra como planeta que abriga a vida, é que podemos transformar de fato nossa narrativa cansada do Iluminismo.

As universidades brasileiras estão sob ataque do governo Bolsonaro. Como você vê esse momento para as pesquisas brasileiras e 0 que fazer quando temos um presidente e um ministro da Educação que são inimigos do conhecimento?

GLEISER - A única saída é um contra-movimento organizado, centrado numa nova visão de mundo em que o foco é a justiça social. Apenas com um novo governo poderemos levantar o país da ruína atual. Os cientistas têm um papel social enorme aqui, e precisam se mobilizar, criar uma voz pública bem mais ampla do que a atual. Sociedade Brasileira para o Progresso da Ciência (SBPC), Academia Brasileira de Ciências (ABC), Medicina, Engenharia, Filosofia, Academia Brasileira de Letras (ABL), Associação Nacional de Pós-Graduação e Pesquisa e Educação (ANPEd), enfim, todas as entidades e associações nacionais de pesquisas devem trabalhar juntas para redefinir o futuro do Brasil.

Fanatismo religioso, ultra direita, militarismo e extrema desigualdade. Elementos amalgamados na realidade brasileira hoje. Quais os perigos dessa mistura?

GLEISER - Essa mistura está levando o país à ruína econômica, cultural e social. Não podemos continuar assim.

Na pandemia que o mundo atravessa, certamente a fé desempenha um papel e a ciência outro. Qual o papel de uma e de outra em crises como essa?

GLEISER - Ciência e fé têm um papel importante e complementar. Mas apenas a fé iluminada pelo saber e não a fé cega e obscurantista de certos movimentos atuais. A ciência tem o papel mais essencial, pois apenas ela pode salvar vidas com tratamentos, com vacinas. É absolutamente incrível que isso não seja óbvio para todos. Mas não é. As pessoas acham que a medicina, a tecnologia cai dos céus, feito um maná sagrado. Mas não é nada disso e cabe aos cientistas, aos médicos explicarem isso para a população.

Tarefa difícil essa a de explicar, em um país em que seu presidente, Jair Bolsonaro, tem por guru o terraplanista Olavo de Carvalho. Sabemos que nem a História e nem a Ciência seguem uma linha reta, em direção cumulativa, progressista, sem retrocessos ou revezes. 
Mas em pleno século 21, como entender quem acredite e defenda que a Terra é plana?

GLEISER - Realmente, é uma mistura de mistério e tragédia. A única explicação que me vem em mente é que esse é um movimento anárquico, cujo objetivo é abalar a credibilidade científica, criando uma comunidade ignorante e obediente. Ou seja, uma espécie de escravidão intelectual, uma massa de gente cega, que nem sabe em que mundo vive. Perdidos, não têm outra opção que a de seguir os líderes que se mostram "poderosos", capazes de desafiar a tudo e a todos, até mesmo o saber científico. As gerações futuras vão rir muito da gente.

Em seu livro $A$ ilha do conhecimento (GLEISER, 2014), você diz que a ciência é mais do que o conhecimento acumulado do mundo e que, se usada tanto para o bem como para o mal, não diz respeito à ciência em si, mas à precariedade da natureza humana, à tendência que temos tanto para criar quanto para destruir. 0 mundo pós-pandemia aprenderá mais a esse respeito sobre a ciência?

GLEISER - Espero que sim. Se há algo que esta pandemia está nos ensinando é a ter humildade com relação à Natureza. A vida não pode ser uma luta entre várias criaturas sem uma dimensão moral, na qual o que importa é sobreviver. Ficamos muito arrogantes com nossos sucessos, e a pandemia nos mostrou que, apesar de sabermos muito, temos muito o que aprender. E, algo essencial, é aprender a conviver com o planeta e seus ecossistemas de forma construtiva e não parasítica.

No mesmo livro, você diz que a ciência é apenas um dos modos de conhecer o mundo e que existem muitos modos de saber, e que estes podem e devem complementar-se e inspirar-se mutuamente. Quais já eram os desafios dessa complementação mútua de vários saberes e quais são esses desafios ainda durante a pandemia e pós-pandemia?
GLEISER - O maior desafio dessa integração dos saberes é o não conhecimento e aceitação do papel de cada um. Da mesma forma que você não quer um médico pilotando o avião em que você voa e o piloto fazendo sua cirurgia, existem classes profissionais que são especializadas e esse saber deve ser respeitado. Por outro lado, muitos desafios atuais requerem pontos de vista plurais, modos de pensar complementares. No caso da pandemia, é claro que a classe médica implementa tratamentos, enquanto os cientistas tentam desenvolver curas e os epidemiologistas desenvolvem modelos para entender como a doença se espalha, o que nos ajuda a combatê-la. 0 governo, as lideranças religiosas e laicas deveriam fazer sua parte mantendo o equilíbrio socioeconômico e emocional das pessoas. No caso da pós-pandemia, teremos as mesmas necessidades de complementaridades dos saberes e dos especialistas, como numa colmeia de abelhas em que cada um tem sua função para o bem comum. 0 foco, como disse antes, deve ser a justiça social.

Em seu livro Criação imperfeita (GLEISER, 2009), você diz que a ciência é uma construção humana criada por nós para explicar o mundo a nossa volta, mas que "verdades" como a lei da gravitação universal de Newton ou a teoria da relatividade especial de Einstein, apesar de brilhantes, funcionam apenas dentro de certos limites e que sempre existirão fenômenos que não poderão ser explicados. Isso tira os méritos e a beleza da ciência?

GLEISER - Pelo contrário! Apenas quando entendemos que a ciência é uma criação humana e, portanto, limitada é que podemos valorizar seus feitos. Transformá-la em dona de uma verdade absoluta é filosoficamente incorreto (a ciência avança e visões de mundo também) e expressa um triunfalismo que apenas leva a uma arrogância injustificada. É justamente quando entendemos como a ciência avança, baseada em nossos instrumentos e teorias, é 
que podemos celebrar os seus grandes feitos. Ninguém deve querer transformar ciência em religião, no sentido de ter omnisciência.

No mesmo livro, você afirma que, após cinco milênios de buscas, é hora de deixar para trás a expectativa de achar explicações finais sobre o mundo, sejam científicas ou religiosas. Diz que sim, somos e sempre seremos criaturas criadoras, mas que nosso foco precisa mudar e que a Natureza está nos dizendo algo de diferente. 0 que a Natureza está nos dizendo agora? Como ouvi-la?

GLEISER - A Natureza está nos dizendo algo muito claro: precisamos mudar nossa atitude de acharmos que somos donos dela, que podemos fazer o que bem quisermos com o mundo natural. Nossa fragilidade é óbvia, e está custando dezenas de milhares de vidas no Brasil e centenas de milhares no mundo. Era certo que teríamos uma nova onda, como ocorreu com a gripe espanhola de 1918, justamente devido a pressões econômicas que vão contra o isolamento social. Precisamos repensar como comemos, como moramos, como usamos energia, como fazemos negócios e como nos relacionamos com as outras criaturas com quem dividimos o planeta. A Terra existiu por bilhões de anos e continuará a existir sem a gente. Mas nós precisamos dela. Essa hierarquia verticalizada de nós sobre a Natureza está totalmente errada.

Quando você ganhou o prêmio Templeton, houve algumas críticas de parte da comunidade científica, justamente por ser um prêmio com ênfase na espiritualidade. Críticas que vão na mesma direção de quem já critica seu ativismo por mais diálogo entre ciência e religião. Poderia falar um pouco mais a respeito?

GLEISER - Quem diz isso nunca leu meus livros e ensaios ou, se leu, não entendeu nada. Certamente, não devem ter lido os meus mais de 100 artigos científicos. 0 diálogo entre a ciência e a religião não visa desmerecer a ciência ou transformá-la em subproduto da fé. São processos completamente diferentes de se ver o mundo e que não devem ser confundidos. Devo dizer que o prêmio Templeton também foi dado a grandes cientistas, dentre eles Freeman Dyson, Martin Rees (o astrônomo real do Reino Unido), John Barrow, Paul Davies, todos eles cosmólogos e teóricos de primeira linha. Esse ano, ganhou o Francis Collins, líder do Projeto Genoma Humano nos Estados Unidos. Me sinto profundamente honrado de fazer parte desse grupo tão distinto. Talvez a culpa seja em parte da mídia brasileira, que falou apenas dos líderes religiosos que ganharam o prêmio: Madre Teresa, Dalai Lama, Desmond Tutu... e nada dos cientistas.

Em seu livro $A$ simples beleza do inesperado (GLEISER, 2016), você, entre outras questões, manifesta imensa preocupação com as mudanças climáticas nas últimas décadas. Nele, você reafirma que a maioria absoluta dos cientistas concorda que o aumento da temperatura global ocorre em função do aumento na poluição atmosférica, consequência do desmatamento e da queima de combustíveis fósseis. A resposta ao problema é de ordem política, econômica, científica, mas não só. Qual a principal dificuldade para o mundo oferecer essa resposta ao problema?

GLEISER - A maior dificuldade é mudar a opinião pública, convencer as pessoas de que o aquecimento global é um risco existencial para a humanidade. As pessoas, até as que acham que o aquecimento global está ocorrendo, pouco fazem no seu dia a dia para mudar seus hábitos. Acham que o ônus é apenas dos governos, das empresas. Embora a responsabilidade seja de governos e empresas, essas instituições respondem aos eleitores e aos consumidores. Quando os consumidores mudam seus hábitos e passam a consumir menos carne, usar menos combustíveis fósseis, menos água, comprar produtos de empresas que têm uma 
ética corporativa que se alinha com o futuro de um planeta saudável e habitável, governos e empresas irão responder. Como fazer isso? Educação, disseminação, conversas públicas, ações comunitárias, programas de TV aberta que divulguem o conhecimento de forma acessível e com urgência.

Você também deve ter tomado conhecimento que, durante a reunião ministerial do dia 22 de abril de 2020, o ministro do Meio Ambiente, Ricardo Salles, disse que o governo brasileiro devia aproveitar a oportunidade trazida pela pandemia, já que o foco da sociedade e da mídia está voltada para o novo coronavírus, e "passar a boiada" e fazer uma "baciada" de mudanças nas regras ligadas à proteção ambiental. Sabemos da importância do Brasil para a questão ambiental. A fala do ministro, portanto, significa um desastre não só para essa política ambiental, mas para a imagem do Brasil no exterior também. Como você avalia?

GLEISER - De forma trágica. É inacreditável que em pleno século 21, sabendo tudo o que sabemos hoje sobre mudanças climáticas como resultado da ação humana, líderes sirvam aos interesses oportunistas do setor agropecuário que, em vez de se reinventar e investir numa agricultura sustentável e limpa, pouco se importa com o que está ocorrendo no mundo e com a destruição ambiental que estão perpetrando. É o pensamento imediatista, visando lucros rápidos e não planos que projetam um futuro planetário em que todos ganham.

\section{Ainda em $A$ simples beleza do inesperado} (GLEISER, 2016), você compara ciência e pescaria. Diz que ambas requerem paciência, tolerância, humildade. A pandemia que 0 mundo enfrenta hoje reforça essa comparação? E a comparação poderia ser adequada a outras áreas?

GLEISER - Nessa analogia entre ciência e a pesca, falo mais do processo criativo científico.
Mas não há dúvida de que pode ser extrapolada para outras atividades criativas - afinal, o que marca o processo criativo, seja de um escritor ou de um cientista buscando por uma vacina, é a persistência, a repetição, as novas tentativas, sempre com o objetivo de aprimorar a obra criativa. 0 resultado, na pescaria o peixe tão desejado, seria o resultado da pesquisa, o texto valioso, a cura de uma nova doença.

No mesmo livro, você diz que o valor de uma geração é o seu legado para as próximas e que pelas crianças você espera que o legado de sua geração (da nossa) seja um planeta melhor, habitado por seres humanos mais espiritualizados, cientes de seu dever moral de preservar a vida a todo custo. Como está essa sua esperança hoje?

GLEISER - Sou um otimista, pois pessimistas já perderam antes de começarem a luta. Vejo que, apesar de todas as dificuldades óbvias que enfrentamos, uma luz diferente começa a iluminar o caminho do respeito ao outro, da diversidade e escolhas que fazemos, uma preocupação maior com a justiça social e o futuro do planeta. Os passos são mais lentos do que gostaria, e talvez acabe funcionando como um catalizador. Não temos nenhum minuto a perder.

Em um artigo publicado na Folha de São Paulo, em 25 de junho de 2006 (GLEISER, 2006), você afirma que é extremamente ingênuo e desnecessário imaginar ser possível um mundo sem religião e que a função da ciência não é tirar Deus das pessoas. Mas e quando a fé obscurantista deseja tirar a ciência do mundo, o que fazer?

GLEISER - Esse é o problema do fanatismo, que é uma forma de cegueira. Os que querem tirar a ciência do mundo são, no mínimo, profundamente hipócritas. Fazem isso usando seus celulares, GPSs, tomando antibióticos etc. Ou seja, usando todas as grandes conquistas 
da ciência e suas aplicações tecnológicas sem a menor autocrítica. De onde eles acham que essas tecnologias todas vêm? É realmente lamentável que hoje, em pleno século 21 , ainda tenhamos que lidar com esse tipo de problema. Temos outros muito mais importantes para enfrentar, e essas pessoas são um atraso, só atrapalham o avanço moral da humanidade. E comprometem o progresso do país.

No prólogo de seu livro $A$ simples beleza do inesperado (GLEISER, 2016), você traz uma epígrafe de Heráclito: “Um homem só se aproxima do seu eu verdadeiro quando atinge a seriedade duma criança que brinca". É um livro em que você conversa com o menino que foi e fala da determinação, ousadia e coragem desse menino. Em outro livro seu, $A$ dança do Universo (GLEISER, 1997), você também fala da infância, referindo-se a um de seus filhos. As crianças são fascinadas pela ciência, já que, gostem ou não da ciência como disciplina, são impregnadas pelo prazer de buscar conhecer. Poderíamos encerrar nossa conversa falando disso?

GLEISER - Claro. Temos muito a aprender com as crianças. São exploradoras natas, sempre tentando aprender algo de novo, com um espírito lúdico e feliz. Nós crescemos e nos esquecemos disso, ficamos casmurros, presos a uma rotina que nos impõe e que nos impomos, uma prisão que pouco nos permite explorar e aprender o novo. Por isso que Isidor Rabi, um dos grandes físicos do século passado, costumava dizer que os físicos são os Peter Pan da sociedade, sempre perguntando sobre o porquê das coisas. Quando perdemos nossa curiosidade, morremos um pouco.

\section{REFERÊNCIAS}

GLEISER, M. A dança do universo - dos mitos da criação ao big-bang. São Paulo: Schwarcz, 1997.

GLEISER, M. A ilha do conhecimento - os limites da Ciência e a busca por sentido. São Paulo: Record, 2014.

GLEISER, M. A simples beleza do inesperado - um filósofo natural em busca de trutas e do sentido da vida. São Paulo: Record, 2016.

GLEISER, M. Conciliando ciência e religião. Folha de S.Paulo, São Paulo, 25 de junho de 2006. Disponível em: https://www1.folha.uol.com.br/fsp/ciencia/ fe2506200601.htm. Acesso em: 16 jul. 2020.

GLEISER, M. Criação imperfeita - cosmo, vida e o código oculto da natureza. São Paulo: Record, 2009.

GLEISER, M. 0 fim da Terra e do Céu - o apocalipse na ciência e na religião. São Paulo: Schwarcz, 2001.

GLEISER, M. Retalhos cósmicos. São Paulo: Schwarcz, 1999.

JOHN TEMPLETON FOUNDATION. Marcelo Gleiser recebe o prêmio Templeton 2019. Pensilvânia, 2019. Disponível em: https://www.templeton.org/ pt/news/. Acesso em: 16 jul. 2020.

Recebido em: 11/03/2021

Aprovado em: 11/03/2021 